\title{
SYNTHESIS OF SILVER NANOPARTICLES USING MORINGA OLEIFERA SEEDS, GLYCYRRHIZA GLABRA STEMS, AND ITS ANTI-METHICILLIN-RESISTANT STAPHYLOCOCCUS AUREUS ACTIVITY
}

\author{
ELISA KALUGENDO, KOUSALYA P* \\ PG \& Research Department of Biochemistry, Bharathidasan College of Arts and Science, Erode Tamil Nadu, India. \\ Email: kousiviswa@gmail.com
}

Received: 03 August 2018, Revised and Accepted: 01 October 2018

ABSTRACT

Objective: The present study focused on synthesizing silver nanoparticles $\left(\mathrm{AgNO}_{3}\right)$ using Moringa Oleifera seeds and Glycyrrhiza glabra stems.

Methods: The synthesized $\mathrm{AgNO}_{3}$ were used to evaluate the antibacterial efficacy of methicillin-resistant Staphylococcus aureus (MRSA) by agar well diffusion method. $\mathrm{AgNO}_{3}$ were produced from silver nitrate using M. oleifera seeds and G. glabra stems.

Results: $\mathrm{AgNO}_{3}$ were characterized using UV-visible spectroscopy at a wavelength of 400-460 nm. AgNO from G. glabra stems showed high antiMRSA activity with $32 \mathrm{~mm}$ zone of inhibition, and M. oleifera seed extract showed $30 \mathrm{~mm}$ inhibition zone of inhibition against MRSA.

Conclusion: The biologically synthesized $\mathrm{AgNO}_{3}$ can be used against MRSA.

Keywords: Methicillin-resistant Staphylococcus aureus, Silver nanoparticles, Glycyrrhiza glabra, Moringa oleifera.

(C) 2019 The Authors. Published by Innovare Academic Sciences Pvt Ltd. This is an open access article under the CC BY license (http://creativecommons. org/licenses/by/4. 0/) DOI: http://dx.doi.org/10.22159/ajpcr.2019.v12i2.28863

\section{INTRODUCTION}

Nanotechnology is the study and application of tiny objects that may be used across different fields such as chemistry, biology, physics, and engineering. Nanoparticle is a major particle which performs as a whole unit in terms of transport and property. Nano means a billionth or 10-9 units. Its size ranges from 1 to $100 \mathrm{~nm}$ because it is too small in size and it occupies a position in various fields of nanoscience and nanotechnology [1]. Silver particles have found tremendous applications in the field of high sensitivity biomolecular detection and diagnostics, antimicrobials and therapeutics; catalysis and microelectronics. Nowadays, there are several methods for the production of nanoparticles such as chemical and physical methods [2].

Staphylococcus aureus is an important cause of serious infections in both hospitals and community. Methicillin-resistant S. aureus (MRSA) include those strains that have acquired a gene giving them a resistance to methicillin antibiotics and essentially all other beta-lactam antibiotics. MRSA was first reported in 1961, soon after methicillin was introduced into the human medicine to treat penicillin-resistant Staphylococci [3].

Moringa oleifera tree is one of the world's most useful trees; in the tropics, it is used as the forage for the livestock; and in many countries, it is used as micronutrient powder, to treat various ailments [4]. The plant is highly valued since almost every part of the tree (leaves, roots, bark, fruits, flowers, immature pods, and seeds) is used as food with high nutritional value. In addition, the plant has been reported to possess antimicrobial properties, and this explains the reason for its wide use in the treatment of human diseases [5].

Glycyrrhiza glabra Linn., family Fabaceae, is the medicinal plant found in Asia, the Mediterranean, and parts of Southern Europe. It is commonly known as Licorice, Liquorice, sweet wood, Mulahatti, and Yastimadhu. The underground unpeeled or peeled stems or roots are used for the treatment of upper respiratory tract ailments including coughs, hoarseness, sore throat, and bronchitis. Ayurveda considers the licorice to be a "rasayana" with implication in the treatment of respiratory and digestive disorders [6]. Silver nanoparticles $\left(\mathrm{AgNO}_{3}\right)$ can be used to treat bacterial diseases [7]. Biosynthesized $\mathrm{AgNO}_{3}$ had several applications in pharmaceutical and large-scale commercial production [8].

The present study focused on synthesizing $\mathrm{AgNO}_{3}$ using $M$. oleifera seeds and G. glabra stems. Synthesized $\mathrm{AgNO}_{3}$ were used to evaluate the antibacterial efficacy of MRSA.

\section{METHODS}

Collection of plant materials

G. glabra stems and M. oleifera seeds were purchased from traditional medicine shop Ellispettai, Erode, Tamil Nadu, India. Collected plant material was washed with water and dried at room temperature. The dried sample was homogenized into a fine powder and used as a raw material and stored in airtight container for further use Fig. 1.

\section{Cold aqueous extraction}

$5.0 \mathrm{~g}$ of dried powder of G. glabra, and M. oleifera was suspended in $50 \mathrm{ml}$ cold distilled water, and the mixture was soaked for $24 \mathrm{~h}$. The suspended solid was filtered through Whatman No.1 filter paper, and the dried crude extracts were stored at $4^{\circ} \mathrm{C}$ for further use.

\section{Bacterial strain isolation}

A total of 5 strains of wound pathogens such as $S$. aureus were isolated from patients infected with wounds. Isolates were maintained at $4^{\circ} \mathrm{C}$ in nutrient media.

\section{Isolation of pathogens}

An aseptically collected wound samples were inoculated with the help of standard inoculating loop on the EMB, MacConkey, and nutrient Agar. The plates were incubated for $24 \mathrm{~h}$ at $37^{\circ} \mathrm{C}$. Following incubation, the growth of bacterial colonies was observed and the results were recorded.

\section{Identification of pathogens}

The isolated pathogens were identified on the basis of Gram's reaction and biochemical characteristics (Mac Faddin, 1980), and the results 
were identified with the help of Bergey's Manual of Systematic Bacteriology.

\section{Synthesis of $\mathrm{AgNO}_{3}$}

For the synthesis of $\mathrm{AgNO}_{3}$, stock solution was prepared by dissolving $1 \mathrm{mM}$ silver nitrate $\left(\mathrm{AgNO}_{3}\right.$; Merck, Mumbai, India) and volume made up to $150 \mathrm{ml}$ with distilled water. $5 \mathrm{ml}$ cold water extract of M. oleifera seeds and G. glabra stems was added to $10 \mathrm{ml}$ of $1 \mathrm{mM} \mathrm{AgNO}_{3}$ solution and allowed to react at room temperature.

\section{Characterization of $\mathrm{AgNO}_{3} \mathrm{UV}$-visible spectroscopy}

The periodic scans of the optical absorbance between 300 and $600 \mathrm{~nm}$ with a UV-visible spectrophotometer (ELICO SL159) at a resolution of $1 \mathrm{~nm}$ were performed to investigate the reduction rate of silver ions by extract of M. oleifera seeds and G. glabra stems.

Antibacterial activity of synthesized $\mathrm{AgNO}_{3}$ (agar well diffusion method)

The antibacterial activities of $\mathrm{AgNO}_{3}$ were carried out against pathogenic strains of MRSA, by agar well diffusion method. Nutrient

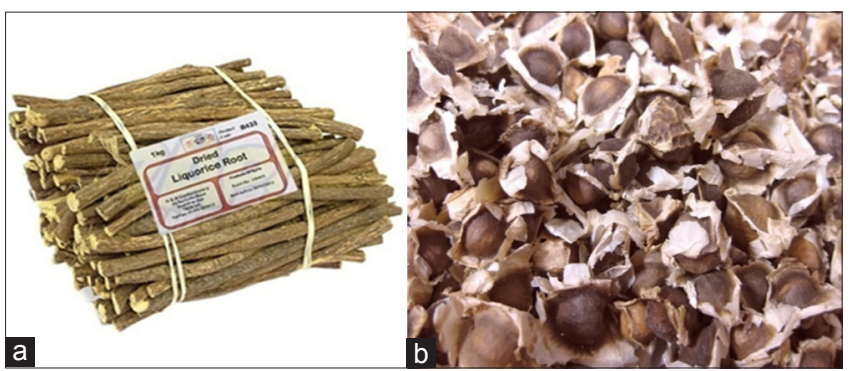

Fig. 1: (a) Glycyrrhiza glabra stems, (b) Moringa oleifera seeds

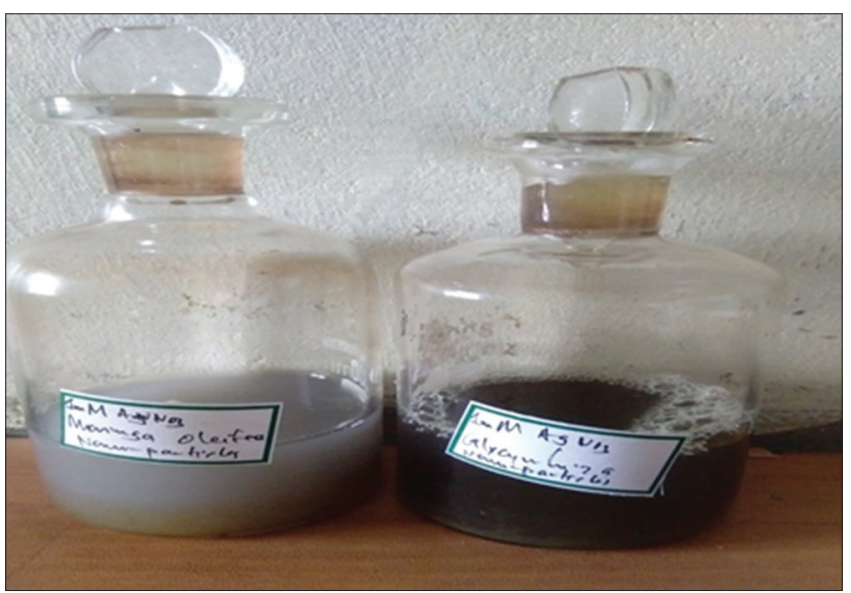

Fig. 2: Synthesized silver nanoparticles using Moringa oleifera seed extract and Glycyrrhiza glabra stem extract
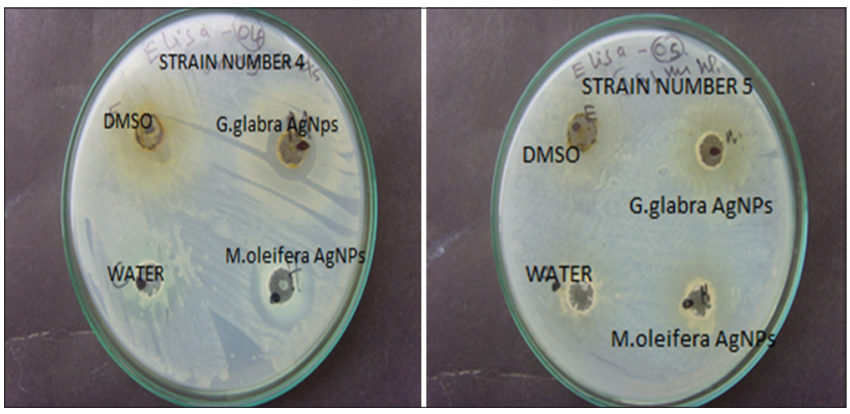

Fig. 3: Antimicrobial activities of synthesized silver nanoparticles from Moringa oleifera seeds and Glycyrrhiza glabra stems agar medium plates were prepared, sterilized, and solidified. After solidification, the formed agar well $(6 \mathrm{~mm}$ in diameter) was added with $100 \mu \mathrm{l}$ of each extract solution, separately to each well. The plates were incubated at $37^{\circ} \mathrm{C}$ for $24 \mathrm{~h}$. Antibacterial activity was evaluated by measuring the zones of inhibition of $\mathrm{AgNO}_{3}$ against the tested bacteria.

\section{REUSLTS AND DISCUSSION}

Identification and biochemical characterization of bacterial isolates

From 15 bacterial strains of $S$. aureus isolated from wound samples, all the strains were identified as $S$. aureus based on the morphological and biochemical characters (Table 1)

Of these 15 strains, two strains were selected according to drug resistant and named as $S$. aureus strains 4 and 5 .

Antimicrobial activity of synthesized $\mathrm{AgNO}_{3}$ against MRSA

Addition of $\mathrm{AgNO}_{3}$ to the cold water extracts of M. oleifera seeds and G. glabra stems extract resulted in the change of the plant extracts from colorless to pale-purple and brown, respectively Figs. 2 and 3.

The formation of nanoparticles in the G. glabra stems extract was indicated by the appearance of brown colour which exhibits surface

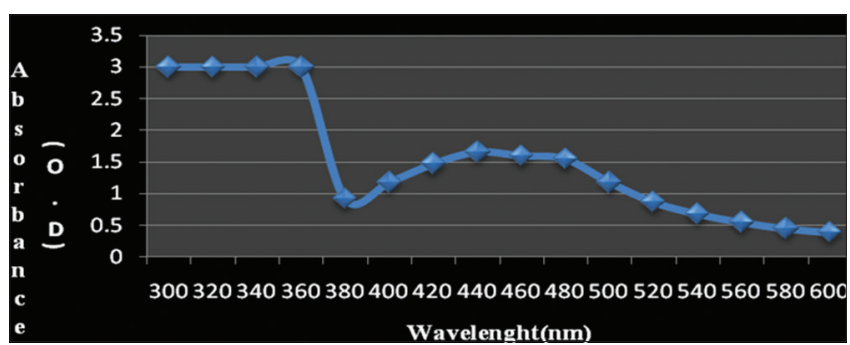

Fig. 4: Synthesized silver nanoparticles from Glycyrrhiza glabra stem extract.

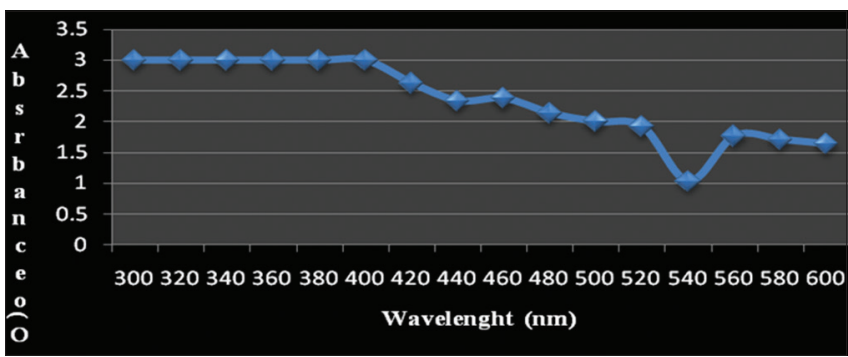

Fig. 5: The synthesized silver nanoparticles from Moringa oleifera seeds extract

Table 1: Biochemical characterization of Staphylococcus aureus isolated from clinical wound samples

\begin{tabular}{ll}
\hline Name of the test & Result \\
\hline Gram stain & Gram positive \\
Indole test & - \\
Methyl red test & + \\
Voges-Proskauer test & + \\
Citrate test & + \\
Catalase test & + \\
Nitrate reduction test & + \\
TSI-Glucose & + \\
TSI-Mannitol & + \\
TSI-Lactose & + \\
TSI-Sucrose & \\
\hline
\end{tabular}

+: Indicates presence and -: Indicates absence 
Table 2: Antibacterial activity of synthesized $\mathrm{AgNO}_{3}$ against MRSA

\begin{tabular}{lll}
\hline Strain & Plant extract & Zone of inhibition \\
\hline Staphylococcus aureus-4 strain & Moringa oleifera seed cold extract & 5 \\
Staphylococcus aureus-4 strain & Glycyrrhiza glabra stem cold extract & 11 \\
Staphylococcus aureus-5 strain & Moringa oleifera cold extract & 30 \\
Staphylococcus aureus-5 strain & Glycyrrhiza glabra cold extract & 32 \\
\hline
\end{tabular}

MRSA: Methicillin-resistant Staphylococcus aureus, $\mathrm{AgNO}_{3}$ : Silver nitrate

Table 3: UV reading for $\mathrm{AgNO}_{3}$ nanoparticles

\begin{tabular}{|c|c|c|c|}
\hline S/NO & Nanometer & $\begin{array}{l}\text { O.D of Glycyrrhiza glabra } \\
\mathrm{AgNO}_{3} \text { nanoparticles }\end{array}$ & $\begin{array}{l}\text { O.D of Moringa oleifera } \\
\mathrm{AgNO}_{3} \text { nanoparticles }\end{array}$ \\
\hline 1 & 300 & 3 & 3 \\
\hline 2 & 320 & 3 & 3 \\
\hline 3 & 340 & 3 & 3 \\
\hline 4 & 360 & 3 & 3 \\
\hline 5 & 380 & 0.925 & 3 \\
\hline 6 & 400 & 1.184 & 3 \\
\hline 8 & 440 & 1.666 & 2.347 \\
\hline 9 & 460 & 1.603 & 2.389 \\
\hline 10 & 480 & 1.554 & 2.144 \\
\hline 11 & 500 & 1.180 & 2.006 \\
\hline 12 & 520 & 0.874 & 1.916 \\
\hline 13 & 540 & 0.678 & 1.031 \\
\hline 14 & 560 & 0.550 & 1.774 \\
\hline 15 & 580 & 0.459 & 1.709 \\
\hline
\end{tabular}

AgNO3: Silver nitrate

plasmon vibrations of $\mathrm{AgNO}_{3}$. M. oleifera seed cold water extract was added to the $\mathrm{AgNO}_{3}$ solution and incubated; the mixture color was changed rapidly from the transparent color to pale-purple color due to the formation of AgNPs. The appearance of pale-purple color was due to the excitation of surface plasmon vibrations of $\mathrm{AgNO}_{3}$ and supports that plants have strong reducing properties.

Synthesized AgNPs of methanol extract from G. glabra stems shown high antimicrobial activities in $S$. aureus 5 strains with inhibition zone of $32 \mathrm{~mm}$, followed by $30 \mathrm{~mm}$ inhibition zone displayed by synthesized AgNPs from cold M. oleifera seeds extract on S. aureus 5 strains. S. aureus 4 strains showed very poor sensitivity reaction toward synthesized AgNPs from cold M. oleifera extract and G. glabra methanol extract with inhibition zones of $5 \mathrm{~mm}$ and $11 \mathrm{~mm}$, respectively (Table 2).

\section{Characterization of $\mathrm{AgNO}_{3} \mathrm{UV}$-visible spectroscopy}

The characterization of synthesized AgNPs was done by UV-visible spectrophotometer, and the recorded UV-absorption spectra exhibited an intense peak at $400 \mathrm{~nm}$ for G. glabra stem extracts and 460 for M. oleifera seeds Figs. 4 and 5. The results are given in Table 3.

\section{CONCLUSION}

The biologically synthesized $\mathrm{AgNO}_{3}$ could be of immense use in the medical field for their efficient antimicrobial function. These findings suggested synthesized $\mathrm{AgNO}_{3}$ from G. glabra extract as a potential antibacterial candidate for the superficial MRSA infection and other bacterial infections.

\section{AUTHORS' CONTRIBUTIONS}

All the authors contributed equally.

\section{CONFLICTS OF INTEREST}

There are no conflicts of interest among the authors.

\section{REFERENCES}

1. Bauer AW, Kirby WM, Sherris JC, Turck M. Antibiotic susceptibility testing by a standardized single disk method. Am J Clin Pathol 1966;45:493-6.

2. Bindhani BK, Panigrahi AK. Biosynthesis and characterization of silver nanoparticle (snps) by using leaf extracts of Ocimum sanctum L (Tulsi) and study of its antibacterial activities. J Nanomed Nanotechnol 2015;S6:8.

3. Boucher H, Miller LG, Razonable RR. Serious infections caused by methicillin-resistant Staphylococcus aureus. Clin Infect Dis 2010;51 Suppl 2:S183-97.

4. Devendra BN, Srinivas N, Talluri VS, Latha PS. Antimicrobial activity of Moringa oleifera Lam., leaf extract, against selected bacterial and fungal strains. Int J Pharm Bio Sci 2011;2:B13-8.

5. Harbottle H, Thakur S, Zhao S, White DG. Genetics of antimicrobial resistance. Anim Biotechnol 2006;17:111-24.

6. Dhanaukar SA, Kulkarkarni RA, Rege NN. Pharmacolgy of medicinal plants and natural products. Indian J Pharm 2000;32:81-118.

7. Raj RS, Divya S, Sindhu S, Kasinathan K, Arumugam P. Studies on synthesis, characterization and application of silver nanoparticles using Mimosa pudica leaves. Int J Pharm Pharm Sci 2014;6:453-5.

8. Sundararajan B, Kumara BD. Biosynthesis of silver nanoparticles in Lagerstroemia speciosa (L.) Pers and their antimicrobial activities. Int J Pharm Pharm Sci 2014;6:30-4. 